\title{
Conformidade no reconhecimento de ativos intangíveis: um estudo na perspectiva da teoria institucional
}

\section{Compliance in the recognition of intangible assets: a study from the perspective of institutional theory}

\section{Conformidad en el reconocimiento de activos intangibles: un estudio en la perspectiva de la} teoría institucional

\section{Bianca Bigolin Liszbinski}

Mestre em Ciências Contábeis na Universidade do Vale do Rio dos Sinos

Professora Substituta do Departamento de Ciências Contábeis da Universidade Federal de Santa

Maria

Endereço: Rua Floriano Peixoto, ${ }^{\circ}$ 1750, Bairro Centro

CEP: 97015-372 - Santa Maria/RS - Brasil

E-mail: biancabigolin@gmail.com

Telefone: + 55 (55) 3307-4018

\section{Clóvis Antônio Kronbauer}

Doutor em Contabilidade y Auditoría na Universidad de Sevilla

Professor do Programa de Pós-Graduação em Ciências Contábeis da UNISINOS

Endereço: Avenida Unisinos, 950, Bairro Cristo Rei

CEP: 93022-000 - São Leopoldo/RS - Brasil

E-mail: clovisk@unisinos.br

Telefone: + 55 (51) 3591-1122

\section{Clea Beatriz Macagnan}

Doutora em Creación, Estrategia y Gestión de Empresas na Universidad Autonoma de Barcelona Professora do Programa de Pós-Graduação em Ciências Contábeis da UNISINOS

Endereço: Rua Almirante Abreu, 139/802, Bairro Rio Branco

CEP: 90420.010 - Porto Alegre/RS - Brasil

E-mail: cleabeatrizm@gmail.com

Telefone: +55 (51) 3388-8443

\section{Tiago Zardin Patias}

Doutorando em Administração na Universidade Federal de Santa Maria

Professor da Universidade Federal do Pampa

Endereço: Rua Barão do Triunfo, 1048, Bairro Centro

CEP: 97573-634 - Santana do Livramento/RS - Brasil

E-mail: tiagopatias@unipampa.edu.br

Telefone: +55 (55) 3243-4540

Artigo recebido em 11/04/2014. Revisado por pares em 30/06/2014. Reformulado em 27/07/2014. Recomendado para publicação em 23/08/2014 por Sandra Rolim Ensslin (Editora Científica). Publicado em 15/12/2014. 


\title{
Resumo
}

Este estudo teve por objetivo analisar a conformidade de um grupo de empresas brasileiras às normativas exigidas para o reconhecimento contábil de ativos intangíveis, à luz da teoria institucional. Trata-se de estudo descritivo de evidências qualitativas e quantitativas que envolveu basicamente a consulta em demonstrações contábeis de uma amostra de empresas classificadas no Índice Bovespa da BM\&FBOVESPA de um espaço temporal que compreende exercícios caracterizados pelas modificações que ocorreram na matriz institucional relacionada aos intangíveis. A análise dos dados consistiu na verificação da aderência das empresas a este novo contexto e no processo de institucionalização da matriz exigida para o reconhecimento dos ativos intangíveis. As evidências observadas revelam uma convergência gradual da amostra estudada à nova matriz institucional relativa aos intangíveis, além de comprovar a possibilidade de utilização dos pressupostos da teoria institucional para explicar a mudança nos procedimentos contábeis aplicados ao reconhecimento desses elementos.

Palavras-chave: Ativos intangíveis. Teoria institucional. Reconhecimento.

\begin{abstract}
This study aimed to analyze the compliance of a group of brazilian companies to the required standards for the accounting recognition of intangible assets, from the point of view of institutional theory. This is the descriptive study of qualitative and quantitative evidence that basically involved the consultation in annual accounts of a sample of companies classified in the BM\&FBOVESPA Bovespa Index of a temporary space that includes exercises characterized by changes that occurred in the institutional matrix related to intangibles. The data analysis consisted in verifying adherence of companies to this new context and in the process of institutionalization of the matrix required for the recognition of intangible assets. The observed evidences reveal a gradual convergence of the studied sample to the new institutional matrix related to intangibles, besides checking the possible use of the assumptions of institutional theory to explain the change in the accounting procedures applied to the recognition of these elements.
\end{abstract}

Keywords: Intangible assets. Institutional theory. Recognition.

\section{Resumen}

Este estudio tuvo como objetivo analizar la conformidad de un grupo de empresas brasileñas hacia las normativas exigidas para el reconocimiento contable de activos intangibles, desde el punto de vista de la teoría institucional. Se trata del estudio descriptivo de evidencias cualitativas y cuantitativas que involucró básicamente la consulta en demostraciones contables de una muestra de empresas clasificadas en el Índice Bovespa de la BM\&FBOVESPA de un espacio temporal que incluye ejercicios caracterizados por las modificaciones que ocurrieron en la matriz institucional relacionada a los intangibles. El análisis de los datos consistió en la verificación de la adherencia de las empresas a este nuevo 
contexto y en el proceso de institucionalización de la matriz exigida para el reconocimiento de los activos intangibles. Las evidencias observadas revelan una convergencia gradual de la muestra estudiada hacia la nueva matriz institucional relativa a los intangibles, además de comprobar la posibilidad de utilización de los presupuestos de la teoría institucional para explicar el cambio en los procedimientos contables aplicados al reconocimiento de esos elementos.

Palabras clave: Activos intangibles. Teoría institucional. Reconocimiento.

\section{Introdução}

A globalização e a inovação tecnológica desencadearam importantes mudanças institucionais na economia mundial. Principalmente em sociedades desenvolvidas ou naquelas em crescente evolução, se observa uma transição da economia industrial, em que os bens tangíveis foram dominantes, para uma economia do conhecimento, com os bens intangíveis sendo determinantes na vantagem competitiva e no aumento do valor econômico das empresas (NAKAMURA, 1999; OLLIER et al., 2010; PETKOV, 2012).

A nova configuração econômica mundial exigiu que a área contábil evoluísse para atender às novas demandas. Diante deste novo contexto, a criação e incorporação das normas internacionais de contabilidade foram um instrumento adotado para adequação às novas necessidades das empresas (OLIVEIRA; LEMES, 2011).

Em referência a sobrevalorização dos intangíveis no contexto econômico atual, a implementação das normas internacionais de contabilidade teve por objetivo facilitar e unificar os procedimentos técnicos adotados para a contabilização de bens como marcas, relacionamentos, pesquisa e desenvolvimento (LEV; CAÑIBANO; MARR, 2005). No âmbito brasileiro, a institucionalização dessas novas regras contábeis refletiu em importantes mudanças nos procedimentos adotados para o reconhecimento contábil desses elementos, especialmente pelas normatizações advindas das Leis $\mathrm{n}^{\mathrm{o}} 11.638 / 2007$ e 11.941/2009 e da implementação do pronunciamento CPC 04/2010, este último, equivalente a International Accounting Standard (IAS) 38.

A observação de normatizações para o reconhecimento dos ativos intangíveis, da mesma forma que para a contabilidade em geral, está relacionada com o ambiente institucional, tanto interno como externo, no qual as entidades estão inseridas. Segundo explica North (1995), as organizações estão à margem das instituições, as quais assumem a função de estabelecer por meio de regras, incentivos e restrições aos negócios, além de disporem da capacidade de influenciar sobre a regulação das relações entre indivíduos ou grupos sociais.

O regramento emanado das instituições pode ser diferenciado de forma mais ampla como formal ou informal, ademais, é por meio das instituições e da sua observação que as entidades buscam legitimar-se na sociedade e alcançar a eficiência nos seus negócios (NORTH, 1994). Relacionando-se a definição de instituições com o reconhecimento contábil de ativos intangíveis, se observa que as normativas contábeis que regem este processo, assumem característica de regras formais por terem um caráter legalista e regulatório. Já os costumes, crenças ou demais práticas não contempladas nas normatizações e aplicadas aos 
procedimentos contábeis, podem ser considerados como regras informais instituídas em cada organização.

O processo de institucionalização dessas regras por parte das organizações e até mesmo as mudanças institucionais provocadas por alterações nestes regramentos se dão de forma contínua e gradual (MAHONEY; THELEN, 2010). Isso significa que as instituições sofrem transformações no decorrer do tempo de acordo com as necessidades ou interesses advindos dos agentes envolvidos neste ambiente. Da mesma forma, a atualização das normativas relativas ao reconhecimento de ativos intangíveis, especialmente aquela originada da convergência dos padrões contábeis brasileiros aos aceitos internacionalmente, caracterizou um avanço na metodologia dos procedimentos e a uniformização das práticas aplicadas a este processo. A adoção da normativa IAS 38 trouxe novos parâmetros à questão contábil desses elementos, pois até então ocorria a aplicação de diferentes práticas tanto no Brasil como internacionalmente (LEV; CAÑIBANO; MARR, 2005; PETKOV, 2011).

Neste contexto, o objetivo geral da pesquisa delimita-se em examinar a conformidade de um grupo de empresas brasileiras à matriz institucional exigida para o reconhecimento de ativos intangíveis em um espaço temporal caracterizado pelas modificações que ocorreram nesta matriz. A utilização dos pressupostos da teoria institucional para explicar este processo, constitui-se relevante especialmente pela possibilidade de compará-los a uma estrutura formal de regramento que ampara os procedimentos contábeis. $\mathrm{O}$ estudo se justifica pela reflexão que propõe ao processo de institucionalização das normativas inerentes aos intangíveis, que conforme Viera (2012), pode sofrer influência da interpretação de preferências por parte dos indivíduos diante das instituições (regras), possibilitando assim, a conformidade com o que está dado ou a transformação do que foi imposto, fruto da ambiguidade do processo interpretativo da nova norma ou significação própria de cada empresa para o procedimento de reconhecimento do ativo intangível.

\section{Revisão de Literatura Teórica}

\subsection{Teoria Institucional}

O período posterior à década de 1970 é marcado pelo avanço dos estudos que analisam a aplicabilidade da teoria institucional no campo das ciências sociais. A partir de então, a perspectiva institucional vem sendo apontada como um dos apanhados teóricos mais promissores para a explicação do funcionamento e avanço da sociedade organizacional (CARVALHO; VIEIRA; SILVA, 2012). Este estudo se encontra na esteira desta perspectiva teórica, uma vez que o Brasil passou a adotar as normas internacionais de contabilidade a partir de 2008, com a vigência da Lei $\mathrm{n}^{0} 11.638 / 2007$, o que alterou sua matriz institucional.

De acordo com a teoria institucional, as instituições são limitações idealizadas pelo homem e que tem por função ordenar a interação humana, seja no campo político, social ou econômico, servindo ainda, como explicação para a evolução das sociedades ao longo do tempo. Portanto, a relação entre indivíduos e a organização da sociedade é somente compreendida com a presença de regras, sendo que estas podem assumir infinitos significados (NORTH, 1995). Nesta perspectiva, a contabilidade que desenvolve a mensuração, reconhecimento e evidenciação dos fenômenos econômicos das empresas, na medida em que 
incorpora as normas contábeis internacionais, passa a adotar um novo comportamento que poderia influir nas relações econômicas.

A vertente econômica da teoria institucional se preocupou em aprofundar a ideia de que a evolução cultural da sociedade provocou mudanças na economia e que esta não é definitivamente estática, caracterizada pelo equilíbrio perfeito e pelas atitudes predominantemente racionais de seus agentes, conforme se afirmava até então. Para Veblen (1965), o comportamento da economia está diretamente relacionado com os costumes e convenções adotados e que a ação de cada indivíduo neste contexto é fator decisivo na evolução econômica, já que os seus conhecimentos e hábitos emolduram este processo evolutivo. Na mesma esteira, Commons (1934) desenvolveu seus estudos aportando que a evolução da economia está relacionada diretamente com questões comportamentais dos indivíduos diante de suas escolhas, podendo estas serem voluntárias ou involuntárias. Sob sua ótica, as instituições originam padrões de conduta coletivos que implicam nas ações e opções individuais.

Trabalhos mais recentes como o de North (1994) e Williamson (2000), autores reconhecidamente ligados ao novo institucionalismo econômico, tiveram um enfoque direcionado mais às relações econômicas no contexto das organizações e buscaram alternativas explicativas à problemática questionadora do equilíbrio perfeito do mercado, visto considerarem que este possui falhas e que as organizações buscam supri-las por meio de instrumentos que as resguardem de incertezas. Conforme análise de Williamson (2000), os três fatores que emolduram as relações econômicas nas organizações compreendem o conjunto de regramentos do ambiente institucional que é base para as transações, as formas de governança estabelecidas e o indivíduo na sua capacidade racional e oportunista. North (1994) adiciona ainda, o sistema de crenças dos atores envolvidos como fator determinante para o entendimento desse processo, devido a ocorrência de variedade de ideias e ideologias em cada indivíduo, sem, no entanto, deixar de observar que são as instituições que eliminam as falhas do mercado, possibilitando eficiência ou permitindo ineficiência.

Considerando o processo evolutivo do pensamento econômico institucional, sugeremse pressupostos que condicionam e explicam as relações no contexto organizacional. Dentre as pressuposições, encontram-se:

a) o reconhecimento das instituições como regras do jogo da sociedade;

b) a presença de regras formais e informais;

c) o condicionamento do comportamento humano às regras do jogo;

d) o institucionalismo fundamentado no seu princípio comum de controle de conflito;

e) a instituição sendo reconhecida como uma ação coletiva que tem efeitos refletidos na ação individual;

f) os fatores formais e informais estruturam o contexto de uma sociedade, determinam o funcionamento e as mudanças econômicas (MACAGNAN, 2013).

Depreende-se, conforme explanações, que as instituições são restrições usadas para regular as relações nas sociedades organizacionais ou entre indivíduos, sendo refletidas por meio de incentivos e oportunidades e podendo ser classificadas como formais ou informais. A limitação formal é aquela oriunda de leis, constituições escritas e formalizadas, geralmente impostas pelo governo ou por algum outro agente com poder coercivo, tendo por função 
facilitar o intercâmbio econômico e político devido a grande diversidade de interesses presentes nessas duas esferas. Por sua vez, as limitações informais são caracterizadas pela sua origem em entes da sociedade e envolvem, por exemplo, costumes, códigos de conduta e normas comportamentais. Características comuns da sociedade moderna, as limitações informais podem ser consideradas fruto da herança cultural e das próprias limitações formais, já que a interpretação e modificação de uma regra formal cria uma informalidade. Tanto formais como informais, estas limitações parametrizam as interações entre determinados atores, caracterizando-se como as regras do jogo na sociedade (NORTH, 1995).

Neste contexto, o ambiente no qual as organizações estão inseridas indica como ela deve atuar e qual o conjunto de regras que implicitamente deve acatar. Em havendo a conformidade com o que está dado, as organizações obtêm além da legitimidade social, o equilíbrio dos negócios, representado, por exemplo, pela redução de incertezas nas transações econômicas no mercado (POLO; VÁZQUEZ, 2008). No caso de não haver a adequação ao estabelecido ou as organizações seguirem apenas critérios próprios, pode-se inferir que estão arriscando a sua sobrevivência (CRUBELLATE, 2007; CARVALHO; VIEIRA; SILVA, 2012).

Retomando o modelo institucional proposto por North (1995), este autor aponta as instituições como normas subjacentes e as organizações como agentes capazes de provocar a mudança dessas instituições, motivados por oportunidades momentâneas ou pela necessidade de alcançar objetivos. Em havendo uma mudança institucional, há uma nova configuração desse ambiente que remete para um novo alinhamento dos atores envolvidos a este novo padrão.

\subsection{Mudança Institucional}

A relação entre as organizações e o ambiente no qual elas estão inseridas, está pautada em uma adequação a requisitos ambientais que propiciem reconhecimento, redução de riscos e incertezas (MEYER; ROWAN, 1977). A questão que emerge é que as organizações devem se ajustar continuamente à configuração desse ambiente dinâmico, que pode se modificar a qualquer momento ou situação.

De acordo com o pensamento institucional, este processo de adaptação às configurações do ambiente é reconhecido como institucionalização e ocorre a partir de uma mudança institucional. Esta mudança é originada a partir da influência de agentes políticos ou econômicos, com capacidade e poder de decisão e são determinadas pelas oportunidades percebidas, seja por mudanças externas ou pelo conhecimento e habilidade desses agentes. Sinteticamente, a relação existente entre organizações e instituições dentro de um ambiente de competição é o fator desencadeante para a mudança institucional (NORTH, 1994).

$\mathrm{O}$ processo de mudança institucional envolve alterações nas regras formais e informais. Em referência às mudanças institucionais provocadas pela modificação das restrições informais, estas ocorrem muito mais gradativamente do que as formais. No caso das limitações informais, as mudanças institucionais podem ser revestidas de certa resistência por envolverem aspectos comportamentais, como por exemplo, desenvolvimento de padrões alternativos pelos indivíduos (NORTH, 1995). De modo geral, o processo de mudança institucional é caracterizado como sendo contínuo, lento e gradativo, embora passível de rupturas e descontinuidade (BELL, 2011). As evidências que referendam esta caracterização 
estão relacionadas principalmente aos interesses e interpretações ambíguas e ao jogo de poder encontrado no ambiente institucional (MAHONEY; THELEN, 2010).

Como já retratado, as organizações adotam um novo padrão institucional para reforçarem a sua legitimidade na sociedade ou para obterem eficiência econômica. Este processo de adoção e internalização de novas práticas ocorre por meio de uma disseminação de ações e significados, caracterizado normalmente, pela convergência das organizações em torno de padrões comuns e homogêneos dentro de um conjunto ambiental (HALL; TAYLOR, 2003).

Em referência a mudança institucional, há de se salientar como ocorre a evolução desse processo internamente nas organizações. A reação das organizações à esta transição pode ocorrer em fases distintas e reflete as suas opções estratégicas. Segundo o modelo proposto por Peng (2003), que analisou as reações dinâmicas do mercado às mudanças econômicas, se observa dois estágios neste processo: fricção institucional e convergência institucional. $\mathrm{Na}$ fase de fricção institucional identifica-se no ambiente a adoção em paralelo de instituições novas e antigas, principalmente pela divergência entre regras formais e informais, visto estas últimas agregarem características de implementação não imediata. $\mathrm{Na}$ fase de convergência institucional, as regras informais passam a estar dispostas às formais, trazendo um reposicionamento organizacional único a nova configuração ambiental.

Assim como em qualquer área organizacional, a contabilidade também está à margem de instituições e pressões ambientais que determinam a sua utilização. Neste campo do conhecimento, sob a ótica da regra, há um conjunto de técnicas e procedimentos definidos formalmente e registrados em manuais, além de rotinas que podem se caracterizar institucionalizadas quando são amplamente aceitas e utilizadas de forma inquestionável. Este enfoque institucional explica os fenômenos contábeis a partir de padrões de comportamento, normas, crenças e procedimentos aos quais as organizações se reportam para ganhar eficiência e legitimidade no ambiente em que estão inseridas (ZUCCOLOTTO; SILVA; EMMERNDOERFER, 2010).

No contexto das mudanças institucionais inserem-se as transformações nas normativas contábeis no mundo todo, face ao processo de convergência às normas contábeis emitidas pelo International Accounting Standards Board (IASB). Estas normas internacionais de contabilidade surgiram como resposta às necessidades das empresas em se adaptarem ao novo contexto de globalização e como uma metodologia minimizadora da problemática da harmonização contábil mundial, possibilitando a estruturação de demonstrações contábeis com características mais aprimoradas de compreensibilidade, relevância, confiabilidade e comparabilidade.

Em específico, cita-se a mudança institucional decorrente da adoção da normativa IAS 38 que regula o tratamento contábil dos ativos intangíveis, tanto no contexto internacional, como particularmente no contexto brasileiro. A matriz institucional dessa normativa traz diretrizes para a identificação de bens intangíveis, a definição de critérios para a sua valorização e os padrões adequados para os relatórios contábeis-financeiros relacionados ao tema.

\subsection{Evolução das Normas Contábeis sobre os Ativos Intangíveis}

Os conceitos de ativos intangíveis, a determinação de que tipos de elementos sejam classificáveis neste grupo, assim como os demais procedimentos contábeis estão de acordo 
com as normativas relacionadas a este tema. Tanto nacional como internacionalmente identificam-se resoluções, normas, leis e deliberações que parametrizam as ações que devem ser executadas no âmbito da contabilidade com relação ao ativo intangível, as quais são editadas por diferentes organizações.

Com relação à estes elementos, tem-se sugerido nos últimos tempos algumas alterações no sistema contábil para que este siga a economia moderna baseada no conhecimento, na qual os intangíveis são recursos críticos e determinantes na vantagem competitiva, no sucesso da economia e na criação de valor para as empresas. Mesmo sendo geralmente aceito que estes ativos são importantes fontes de desempenho, ainda depara-se com regras contábeis restritivas que impedem em determinados casos, por exemplo, desses ativos serem incluídos no balanço patrimonial das empresas. A discussão que ocorre é que os organismos profissionais e regulamentares não estão acompanhando às rápidas mudanças no ambiente quanto aos ativos intangíveis. A reação tardia dos reguladores, por consequência, abre precedente para a criação e utilização de normas próprias em cada organização (LEV; CAÑIBANO; MARR, 2005).

Normalmente a adoção de diferentes práticas advém da necessidade específica de cada empresa. Independentemente da contabilidade internacional buscar a harmonização de processos e primar pela qualidade nas divulgações, informações sobre intangíveis nas contas anuais são escassas em comparação com a importância desses elementos nas empresas (LENORMAND; TOUCHAIS, 2008; BOULERNE; SAHUT, 2010). Exemplificando, cita-se a necessidade cada vez maior das empresas em melhorar a transparência e a comunicação com as partes interessadas, especialmente devido ao avanço tecnológico e para assegurar a confiança de investidores. Diante disso, observam-se metodologias alternativas para relatar e medir os ativos intangíveis dentro das organizações, complementando dessa forma, as normas contábeis vigentes (MOURTISEN; BUKH; MARR, 2005).

Mesmo com a busca pela uniformização internacional da contabilidade, ainda se encontram diferentes entendimentos para o tratamento contábil destes elementos. Questões que envolvem o reconhecimento, valoração e divulgação são aplicadas distintamente, seja pelo fato de serem seguidas instruções de diferentes organismos reguladores ou pela legislação própria de cada país (SOTO; SALAZAR; GALVIS, 2006). Diante desse cenário, a apresentação de informações consistentes sobre estas rubricas se constitui em um desafio tanto para os sistemas contábeis como para os profissionais da área.

Organizações reguladoras da área contábil se preocuparam em desenvolver padrões que propiciem uma maior valorização dos intangíveis e possibilitem às entidades e investidores informações necessárias para a tomada de decisões. O IASB configura-se como uma organização com expressão internacional, independente, situada em Londres (GrãBretanha) e formada por entidades profissionais de mais de 140 países, inclusive do Brasil. A principal missão do IASB é buscar alternativas que resultem na harmonização das práticas contábeis internacionalmente, por meio da criação e publicização de pronunciamentos que sirvam de referência aos procedimentos contábeis adotados por diferentes países.

O tratamento contábil de ativos intangíveis de acordo com o IASB está normatizado segundo os padrões descritos no Quadro 1. Entre as normativas, constam padrões expedidos especificamente para os ativos intangíveis e também aqueles que podem de alguma forma refletir na contabilização destes elementos. 
Quadro 1- Regulação contábil de ativos intangíveis conforme o IASB

\begin{tabular}{|c|l|}
\hline Emissão & Descrição \\
\hline 1988 & International Accounting Standard 36-Impairment of Assets \\
\hline 2002 & SIC Interpretation 32 - Intangible Assets-Web Site Costs \\
\hline 2004 & $\begin{array}{l}\text { International Accounting Standard 8 - Accounting Policies, Changes in Accounting Estimates and } \\
\text { Errors }\end{array}$ \\
\hline 2004 & International Accounting Standard 38 - Intangible Assets \\
\hline 2008 & International Financial Reporting Standard 3-Business Combinations \\
\hline
\end{tabular}

Fonte: Adaptado de IASB (2013).

No âmbito brasileiro, os procedimentos contábeis aplicados aos ativos intangíveis acompanharam as modificações que ocorreram na contabilidade em geral. A proposição dos parâmetros inerentes a estes ativos está voltada especialmente para a qualificação das informações contábeis-financeiras disponibilizadas aos diferentes tipos de usuários das empresas.

De acordo com os dados apresentados no Quadro 2, se observa a vigência de diversas normativas que refletem direta ou indiretamente nas práticas contábeis relativas aos bens imateriais. Além do CPC 04/2010 que especifica os critérios para o reconhecimento, mensuração do valor contábil e divulgação dos intangíveis e equipara estes procedimentos àqueles preconizados pela IAS 38, a legislação brasileira, as normas contábeis editadas pelo Conselho Federal de Contabilidade (CFC) e demais CPC's, instrumentalizam a contabilidade desses bens.

Quadro 2 - Normatização contábil inerente aos ativos intangíveis no Brasil

\begin{tabular}{|c|l|}
\hline Órgão Regulador & \multicolumn{1}{|c|}{ Normativa } \\
\hline Legislação Federal & Lei 6.404 (1976); Lei 11.638 (2007); Medida Provisória 441 (2008); Lei 11.941 (2009) \\
\hline CPC & $\begin{array}{l}\text { Pronunciamento Conceitual Básico; ICPC 09 (2009); CPC 01 (2010); CPC 04 (2010); } \\
\text { CPC 15 (2011); CPC 26 (2011) }\end{array}$ \\
\hline CFC & NBC T 19.8 (2008); NBC TG 04 (2010); NBC TG 15 (2011) \\
\hline
\end{tabular}

Fonte: Elaborado pelos autores.

Além das normatizações advindas destes órgãos regulamentadores, cita-se as exigências demandadas pela Comissão de Valores Mobiliários (CVM) às empresas que atuam em negociações no mercado de valores mobiliário brasileiro. Dentre as normativas da CVM que orientam sobre práticas contábeis que influenciam na contabilização dos ativos intangíveis, cita-se especialmente: a) a Deliberação 488/2005 que trata da apresentação em separado dos intangíveis, seu método e período de amortização; b) a Instrução 469/2008 que dispõe da obrigatoriedade da implementação nas normas contábeis aceitas internacionalmente; e c) a Deliberação 553/2010 que aprova e torna obrigatório os procedimentos constantes no CPC 04/2010.

Com a evolução dos regramentos relativos aos elementos em estudo, seja pela sua criação ou modificação, espera-se uma convergência das entidades a esta nova lógica. Todavia, sabe-se que no campo da contabilidade as mudanças provocadas pela criação de 
novas regras ou avanço daquelas já existentes podem não ser adotadas em sua totalidade (GUERREIRO, 2006).

No contexto dos ativos intangíveis, mesmo a criação ou transformação de uma regra ter a participação de diversas organizações envolvidas no ambiente da contabilidade as quais buscam o avanço das técnicas dessa área, isso não é fator determinante para que esta nova norma seja adotada integralmente pelas empresas. A não aplicação destas mudanças traz a possibilidade de surgir procedimentos informais adotados pelas empresas, fruto dos seus costumes ou políticas próprias.

\section{Procedimentos Metodológicos}

A pesquisa é caracterizada como descritiva quanto aos seus objetivos, pois descreve as implicações observadas para o reconhecimento dos ativos intangíveis da amostra, considerando-se a institucionalização da IAS 38. Adicionalmente, identifica as estruturas formais e práticas operacionais aplicadas que possam influenciar neste reconhecimento. Este tipo de estudo caracteriza-se pela observação, análise e correlação de fatos ou variáveis sem manipulá-los. Procura descobrir também, a frequência com que um fenômeno ocorre, sua relação e conexão com outros, sua natureza e propriedades (KMETEUK FILHO, 2005).

Quanto ao processo adotado para a investigação, este se caracteriza como qualitativo e quantitativo. A ênfase dos estudos qualitativos está na interpretação dos processos e significados adotados por determinadas estruturas e organizações (GODOI; BALSANI, 2010), sendo que esta pesquisa envolve a análise interpretativa e descritiva das práticas contábeis relativas ao reconhecimento dos ativos intangíveis. A abordagem quantitativa é desenvolvida neste processo por meio da mensuração dos dados do reconhecimento de bens intangíveis e sua posterior análise utilizando-se técnicas de estatística descritiva.

Para o desenvolvimento do estudo foi selecionada uma amostra não probabilística, em uma população formada pelas empresas classificadas no Índice Bovespa - Ibovespa - da BM\&FBOVESPA. Em Agosto de 2012 este índice era formado por 64 empresas de diferentes setores de atuação. Para a composição da amostra do estudo foram excluídas desta população 11 empresas constituídas como holding pela sua caracterização peculiar de atuar basicamente com o objetivo de participar societariamente em outras entidades e mais 3 empresas que não disponibilizaram as demonstrações contábeis de todos os anos para os quais se propõe a análise. Dessa forma, a amostra final deste estudo compõe-se de 50 empresas.

As evidências para o desenvolvimento do estudo foram obtidas por meio de consulta documental às demonstrações contábeis individuais das empresas controladoras, abrangendo balanço patrimonial e notas explicativas publicados no site da CVM e/ou BM\&FBOVESPA, referentes ao período de 2006 a 2012. Este espaço de tempo foi definido para o estudo, pois agrega exercícios anteriores e posteriores a convergência aos padrões internacionais de contabilidade no Brasil e que abarcam a alteração na matriz institucional aplicada aos ativos intangíveis.

As evidências coletadas foram tabuladas de forma a identificar o conjunto de regramentos adotados pelas empresas, tendo-se por base as obrigatoriedades exigidas para o reconhecimento dos ativos intangíveis. A instrumentalização desta fase ocorre por meio da comparação das informações contábeis evidenciadas sobre intangíveis no balanço patrimonial 
e notas explicativas das entidades com os critérios descritos no Quadro 3 que apresentam-se como obrigatórios ao reconhecimento desses bens.

Os padrões selecionados envolvem procedimentos contábeis compulsórios que as empresas deveriam adotar e têm por base a legislação vigente, além das orientações do CPC 04/2010. É por meio desta análise que se verificou a institucionalização das normativas exigidas e confirmaram-se as principais políticas adotadas pelas empresas com relação ao reconhecimento dos seus ativos intangíveis.

\begin{tabular}{|c|c|}
\hline Critério & Descrição do Padrão Contábil \\
\hline$a$ & $\begin{array}{l}\text { Descrição de políticas contábeis adotadas na mensuração dos ativos intangíveis, incluindo formas } \\
\text { e critérios de valoração utilizados }\end{array}$ \\
\hline$b$ & Distinção entre ativos intangíveis gerados internamente e outros ativos intangíveis \\
\hline$c$ & Diferenciação entre ativos intangíveis com vida útil indefinida e definida \\
\hline$d$ & $\begin{array}{l}\text { Definição do prazo de vida útil e taxas de amortização para ativos intangíveis com vida útil } \\
\text { definida }\end{array}$ \\
\hline $\boldsymbol{e}$ & Apresentação do método de amortização para ativos intangíveis com vida útil definida \\
\hline$f$ & Apresentação de eventual amortização acumulada mais as perdas no valor recuperável \\
\hline$g$ & Conciliação do valor contábil no início e no final do período \\
\hline $\boldsymbol{h}$ & $\begin{array}{l}\text { Descrição de adições, indicando as que se referem a desenvolvimento interno, as adquiridas, ou } \\
\text { aquelas adquiridas por combinação de negócios }\end{array}$ \\
\hline$i$ & Divulgação de reduções decorrentes de ativos que tiveram perda por desvalorização \\
\hline$j$ & Distinção entre classes de ativos intangíveis \\
\hline $\boldsymbol{k}$ & $\begin{array}{l}\text { Para os ativos intangíveis com vida útil indefinida, apresentação do valor contábil e razões dessa } \\
\text { classificação }\end{array}$ \\
\hline$l$ & $\begin{array}{l}\text { No caso de ativos intangíveis adquiridos por subvenção governamental, apresentação do valor } \\
\text { justo inicialmente reconhecido e valor contábil }\end{array}$ \\
\hline$m$ & Existência e os respectivos valores contábeis de ativos intangíveis cuja titularidade é restrita \\
\hline$n$ & $\begin{array}{l}\text { Existência e os respectivos valores contábeis de ativos intangíveis oferecidos como garantia de } \\
\text { obrigações }\end{array}$ \\
\hline $\boldsymbol{O}$ & Divulgação do total de gastos com pesquisa e desenvolvimento como despesas do período \\
\hline$p$ & $\begin{array}{l}\text { Descrição de ativos intangíveis significativos, controlados pela entidade, mas que não são } \\
\text { reconhecidos como ativos porque não atendem aos critérios normativos }\end{array}$ \\
\hline$q$ & $\begin{array}{l}\text { Classificação do intangível no ativo não circulante conforme deliberação CVM 488/2005 (Divisão } \\
\text { do ativo em circulante e não circulante }\end{array}$ \\
\hline$r$ & $\begin{array}{l}\text { Classificação do intangível no permanente (investimentos; imobilizado; intangíveis; diferido) } \\
\text { conforme Lei } 11.638 / 2007\end{array}$ \\
\hline$S$ & Classificação do intangível no ativo não circulante conforme MP 449/2008 e Lei 11.941/2009 \\
\hline
\end{tabular}

A análise dos resultados obtidos centra-se em demonstrar a evolução da aderência das empresas às obrigatoriedades para o reconhecimento dos ativos intangíveis e em diferenciar essas evidências em dois períodos principais: 2006 a 2009 e 2010 a 2012. O primeiro período caracteriza-se pela antecedência à adoção do CPC 04 enquanto o segundo abrange exercícios com a obrigatoriedade da implementação desta nova normativa. A opção por analisar as evidências destes dois períodos em separado refere-se ao fato da vigência do CPC 04 a partir 
do ano de 2010 no Brasil, o que provocou a obrigatoriedade das empresas adotarem a nova metodologia de tratamento aos ativos intangíveis, equiparada às normas internacionais de contabilidade.

Posteriormente, faz-se uma relação das evidências identificadas com os pressupostos da teoria institucional. Esta reflexão busca demonstrar a aderência das empresas a matriz institucional imposta ao processo de reconhecimento dos ativos intangíveis, além de verificar a convergência dessas empresas às mudanças que ocorreram nesta matriz no período analisado.

\section{Análise e Discussão dos Resultados}

\subsection{Aderência aos Parâmetros Normativos para o Reconhecimento de Ativos Intangíveis}

Dentre os padrões contábeis obrigatórios para o reconhecimento dos ativos intangíveis que foram pesquisados, segundo as divulgações efetuadas pelas empresas, identifica-se uma heterogeneidade no que se refere a utilização dos procedimentos previstos na IAS 38, principalmente até o ano de 2010. Mesmo com a indicação proposta pela CVM por meio da deliberação $\mathrm{n}^{0} 488 / 2005$ de que as empresas brasileiras de capital aberto que possuíam negociações em mercados internacionais deveriam adotar as normas internacionais de contabilidade, entre o período de 2006 à 2009 observa-se a ocorrência, em maior incidência, de diferentes procedimentos adotados pelas entidades.

A identificação de diferentes práticas relaciona-se com o fato das empresas brasileiras estarem vinculadas às normas internas do país, especialmente à Lei $n^{\circ}$ 6.704/1976, que não contemplava tratamento especial aos ativos intangíveis, sendo que apenas indicava a forma de classificação desses bens. Adicionalmente, algumas empresas divulgavam em notas explicativas, de maneira superficial, as políticas contábeis que adotavam com estes elementos.

Ressalta-se que a análise por meio de parâmetros oriundos do CPC 04/2010 é a que fornece maiores subsídios para se identificar a conformidade das empresas quanto aos requisitos ao reconhecimento dos ativos intangíveis, visto que a amostra em estudo é composta, exclusivamente, por entidades brasileiras de capital aberto que estariam aderentes às normas internacionais de contabilidade desde 2006, conforme deliberação CVM n $488 / 2005$.

Os padrões normativos descritos no Quadro 3 tiveram uma maior unicidade quanto ao seu atendimento a partir do ano de 2010, pela implementação da obrigatoriedade dos pressupostos do CPC 04. A interação de grande parte das empresas a essa nova normativa foi observada em especial em determinados padrões que tiveram a sua utilização a partir desse exercício, como por exemplo: divulgação de nota geral sobre os ativos intangíveis; indicação do prazo de vida útil e taxas de amortização para ativos intangíveis com vida útil definida; apresentação do método de amortização para ativos intangíveis com vida útil definida; conciliação do valor contábil no início e no final do período; e distinção entre classes de ativos intangíveis.

Mesmo assim, constatou-se que determinados padrões contábeis exigidos para o reconhecimento dos ativos intangíveis ainda não são atendidos mesmo no ano de 2012. Como exemplo de obrigatoriedade não observada cita-se: a divulgação de reduções decorrentes de 
ativos que tiveram perda por desvalorização (19 casos); a distinção entre ativos intangíveis gerados internamente e outros ativos intangíveis (13 casos); a descrição de adições, indicando as que se referem a desenvolvimento interno, as adquiridas, ou aquelas adquiridas por combinação de negócios (13 casos); a apresentação de eventual amortização acumulada mais as perdas no valor recuperável (11 casos); e apresentação do valor contábil e razões da classificação dos ativos intangíveis com vida útil indefinida (08 casos).

Os dados apresentados nas Tabelas 1 e 2 exemplificam as oscilações identificadas na conformidade das empresas aos critérios obrigatórios para o reconhecimento dos ativos intangíveis descritos na seção metodológica deste estudo. Observou-se variações entre 17\% até $100 \%$ no atendimento às obrigatoriedades, sendo que na média houve uma elevação na conformidade da amostra a partir do exercício de 2010, o qual é caracterizado pela implementação do CPC 04/2010 no âmbito brasileiro.

A empresa que se destaca em nível de conformidade para o reconhecimento de ativos intangíveis é a COPEL - Companhia Paranaense de Energia, atingindo 100\% de atendimento aos padrões do período 2006 a 2012. Mesmo reconhecendo bens imateriais em apenas três exercícios do período analisado, houve o cumprimento de todas as exigências.

Em seguida, a empresa OI S.A. apresentou 99\% de aderência aos padrões normativos analisados. Este percentual médio condiz com os níveis identificados entre o período de 2006 (100\%), 2007 (92\%), 2008 (100\%), 2009 (100\%), 2010 (100\%), $2011(100 \%)$ e 2012 (100\%). Outras empresas que se destacam pelos níveis médios elevados de atendimento aos requisitos de reconhecimento contábil dos ativos intangíveis foram a Gerdau S.A. com 96\%, a Companhia B2W e as Lojas Americanas, ambas com 93\%.

Tabela 1 - Maiores níveis de conformidade do reconhecimento de ativos intangíveis

\begin{tabular}{lcccccccc}
\hline Empresas & $\mathbf{2 0 0 6}$ & $\mathbf{2 0 0 7}$ & $\mathbf{2 0 0 8}$ & $\mathbf{2 0 0 9}$ & $\mathbf{2 0 1 0}$ & $\mathbf{2 0 1 1}$ & $\mathbf{2 0 1 2}$ & Média \\
\hline COPEL - Companhia Paranaense de Energia & - & - & 1,00 & 1,00 & - & - & - & 1,00 \\
OI S.A. & 1,00 & 0,92 & 1,00 & 1,00 & 1,00 & 1,00 & 1,00 & 0,99 \\
Gerdau S.A. & 0,92 & 0,92 & 0,92 & 1,00 & 1,00 & 1,00 & 1,00 & 0,96 \\
B2W - Companhia Global do Varejo & 0,75 & 0,75 & 1,00 & 1,00 & 1,00 & 1,00 & 1,00 & 0,93 \\
Lojas Americanas S.A. & 0,75 & 0,75 & 1,00 & 1,00 & 1,00 & 1,00 & 1,00 & 0,93 \\
\hline
\end{tabular}

Fonte: Dados da pesquisa.

Em contraste, a empresa CPFL Energia S.A. é aquela que apresenta o menor nível de conformidade $(17 \%)$, considerando-se as informações evidenciadas. Observa-se que esta empresa manteve o mesmo nível de conformidade em todo período, não progredindo no atendimento das exigências.

Tabela 2 - Menores níveis de conformidade do reconhecimento de ativos intangíveis

\begin{tabular}{lcccccccc}
\hline Empresas & $\mathbf{2 0 0 6}$ & $\mathbf{2 0 0 7}$ & $\mathbf{2 0 0 8}$ & $\mathbf{2 0 0 9}$ & $\mathbf{2 0 1 0}$ & $\mathbf{2 0 1 1}$ & $\mathbf{2 0 1 2}$ & Média \\
\hline JBS S.A. & 0,00 & 0,08 & 0,27 & 0,33 & 0,62 & 0,62 & 0,62 & 0,36 \\
Eletropaulo Metropolitana Elet. São Paulo S.A & 0,00 & 0,00 & 0,00 & 0,18 & 0,64 & 0,64 & 0,64 & 0,30 \\
Klabin S.A. & 0,00 & 0,00 & 0,08 & 0,25 & 0,50 & 0,50 & 0,50 & 0,26 \\
Companhia de Transmissão Energia Elétrica Paulista & 0,00 & 0,00 & 0,00 & 0,18 & 0,36 & 0,36 & 0,36 & 0,18 \\
CPFL Energia S.A. & - & 0,17 & 0,17 & 0,17 & 0,17 & 0,17 & 0,17 & 0,17 \\
\hline
\end{tabular}

Fonte: Dados da pesquisa. 
As empresas Companhia de Transmissão Energia Elétrica Paulista, Klabin S.A., Eletropaulo Metropolitana e JBS S.A., apresentaram respectivamente, níveis nédios de conformidade aos parâmetros normativos de reconhecimento de ativos intangíveis de $18 \%$, $26 \%, 30 \%$ e $36 \%$. Exemplificadamente, o percentual médio de $36 \%$ verificado na JBS S.A., envolve os níveis identificados em 2006 (0\%), 2007 (8\%), 2008 (27\%), 2009 (33\%), 2010 (62\%), $2011(62 \%)$ e $2012(62 \%)$.

Conforme ilustração do Gráfico 1, pode-se observar o comportamento evolutivo da aderência das empresas da amostra aos requisitos obrigatórios para o reconhecimento dos ativos intangíveis. A média geral da conformidade para o reconhecimento dos ativos intangíveis foi de $64 \%$ no período compreendido entre 2006 a 2012. Muito embora este índice seja considerado como não satisfatório, revela-se um crescimento e uma tendência de estabilização nesta conformidade após o ano de 2010 , que se situa acima de $80 \%$.

Os anos iniciais analisados (2006 e 2007) apresentam um moderado percentual de atendimento aos requisitos legais, com índices próximos a 30\%. Entre 2008 e 2009, anos caracterizados pela convergência brasileira às normas internacionais de contabilidade, devido ao vigor da Lei 11.638/2008, registrou-se uma considerável elevação na conformidade do reconhecimento dos intangíveis, atingindo $60 \%$ e $69 \%$, respectivamente.

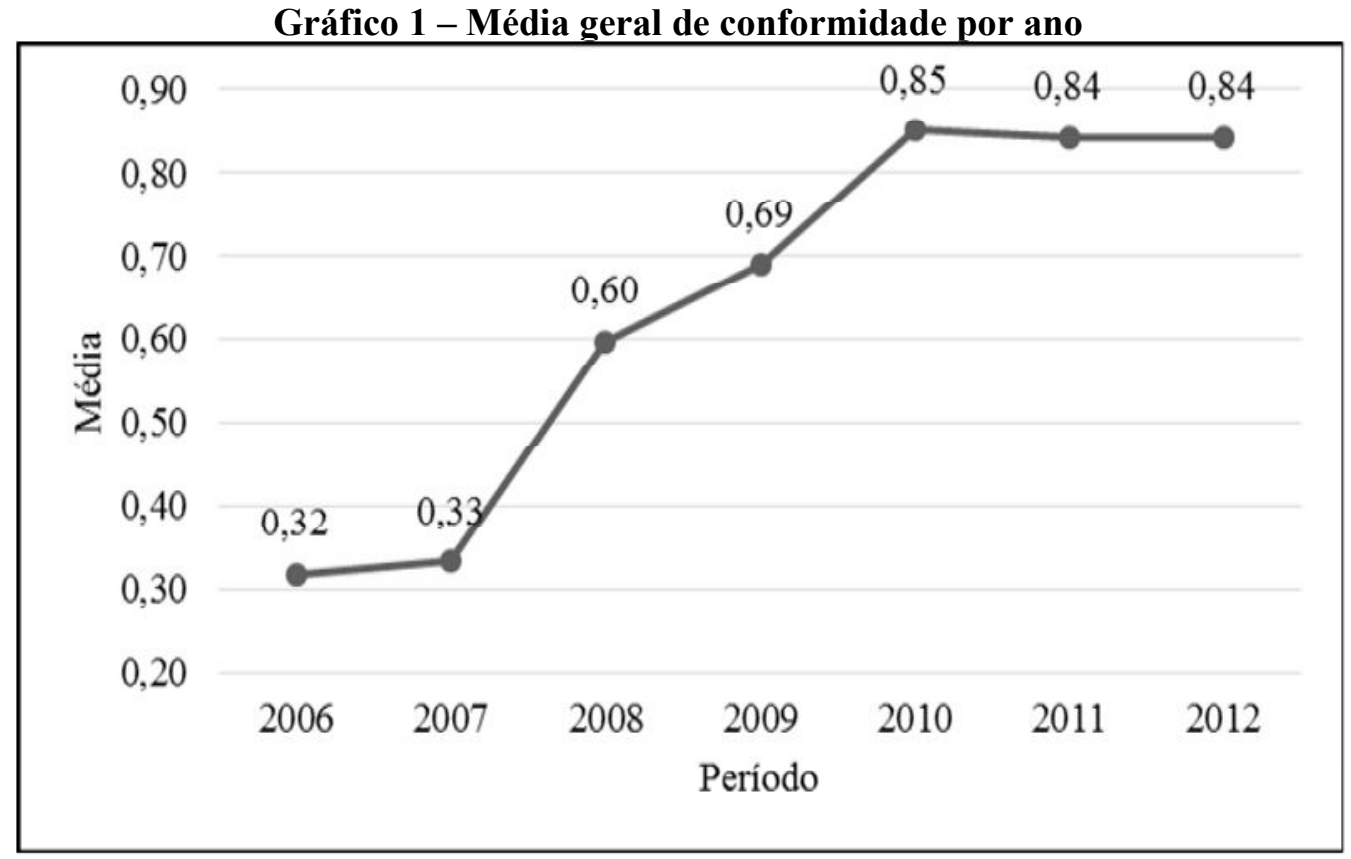

Fonte: Dados da pesquisa.

O período posterior a 2009 registra novamente uma elevação, principalmente pelo fato de que em 2010 há a obrigatoriedade das empresas atenderem aos requisitos do CPC 04/2010, que trata especificamente dos bens intangíveis. A conformidade normativa nos procedimentos adotados pelas empresas para o reconhecimento desses elementos passou de $69 \%$ em 2009 para $85 \%$ em 2010, sendo que nos anos seguintes (2011 e 2012) os percentuais mantiveram-se praticamente estáveis.

De modo geral, infere-se que a vigência das disposições constantes no CPC 04, a partir do exercício de 2010, foi fator determinante para o aumento da conformidade das empresas 
pesquisadas. Esse resultado demonstra que a adesão às novas configurações das regras normativas relacionadas aos ativos intangíveis se deu de forma gradativa durante o período analisado e tende a manter-se em níveis equilibrados nesta amostra.

Gráfico 2 - Média geral de conformidade por setor de atuação

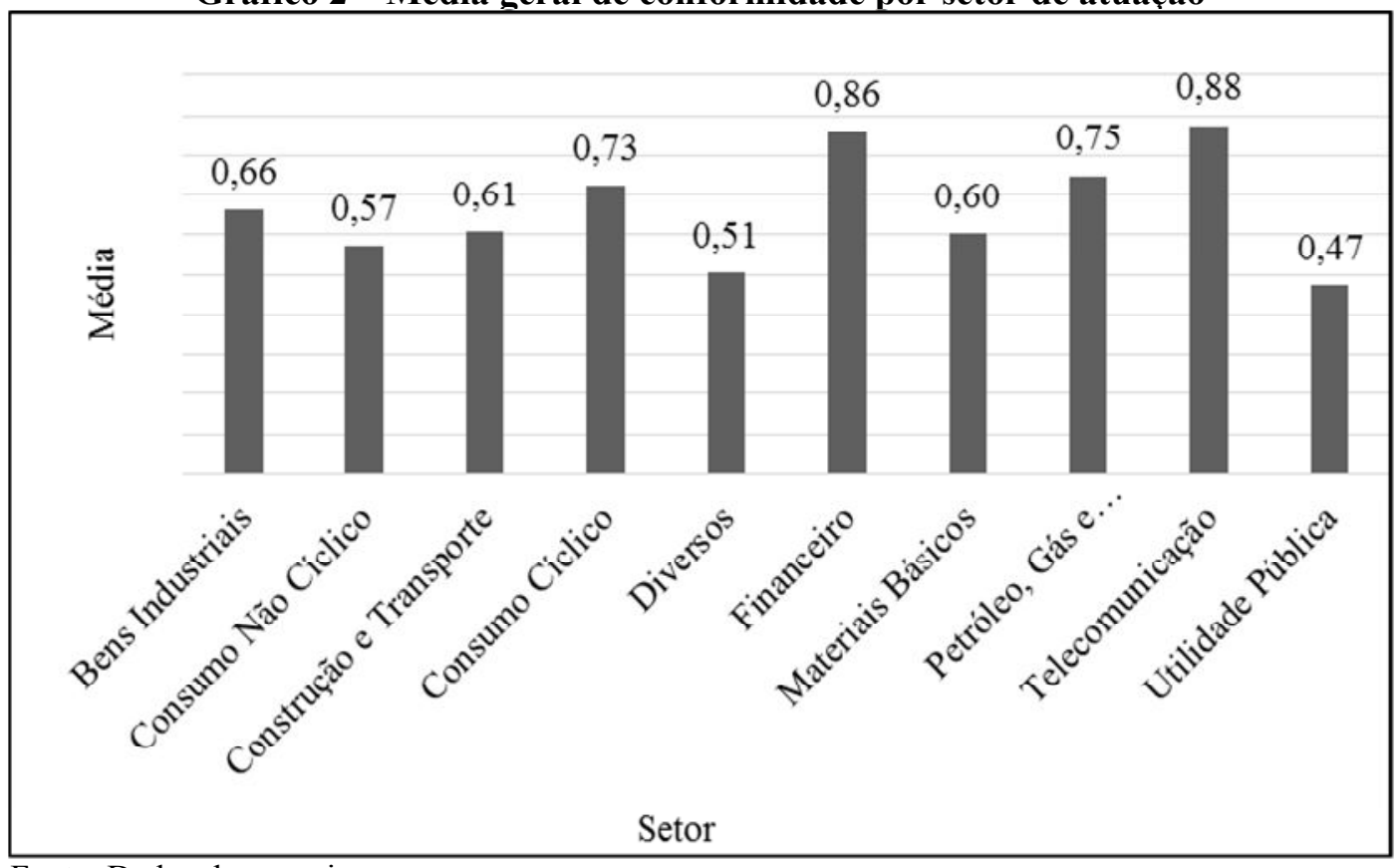

Fonte: Dados da pesquisa.

Dentre as empresas da amostra, aquelas pertencentes aos setores de Telecomunicações e Financeiro são as que apresentam maiores índices de atendimento aos padrões pesquisados, conforme se destaca no Gráfico 2. Respectivamente, identificou-se $88 \%$ e $86 \%$ de conformidade aos requisitos legais nestes setores, entre o período de 2006 a 2012.

Diferenciadamente, as entidades representativas do setor de Utilidade Pública são as que apresentam, na média, a menor conformidade aos padrões exigidos para $\mathrm{o}$ reconhecimento dos ativos intangíveis. Observou-se neste setor, a aplicabilidade de $47 \%$ dos padrões obrigatórios para este procedimento.

O processo de institucionalização dos parâmetros normativos para o reconhecimento dos ativos intangíveis evoluiu positivamente em cada setor analisado. Conforme se observa no Gráfico 3, o período de 2010-2012 apresenta índices de conformidade relativamente superiores aos identificados entre 2006-2009 em todas as áreas.

A vigência do CPC 04 pode ser reconhecida como fator determinante para a qualificação dos procedimentos adotados. O setor de construção e transporte apresentou a maior elevação comparando-se os dois períodos analisados. Entre 2006 e 2009, apresentou índice de conformidade médio de 35\%, passando para 95\% entre 2010 e 2012. 
Gráfico 3 - Média da conformidade antes e após a vigência do CPC 04 por setor de atuação

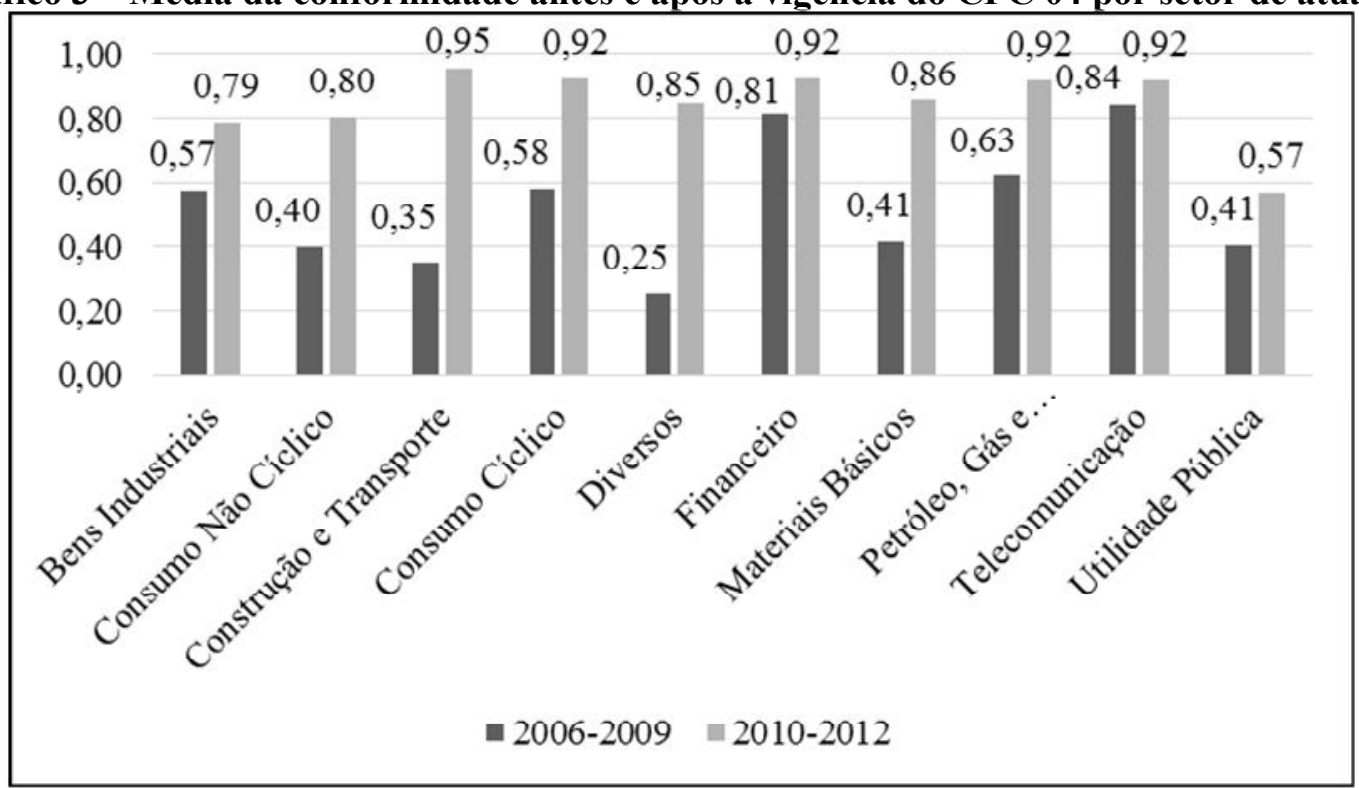

Fonte: Dados da pesquisa.

O setor financeiro e de telecomunicações apresentaram as menores variações de conformidade entre os dois períodos. Respectivamente, estes setores observaram $81 \%$ e $84 \%$ dos itens obrigatórios para o reconhecimento dos intangíveis entre 2006-2009, passando a atender $92 \%$ dos critérios no período de 2010-2012.

\subsection{Reflexos das Mudanças na Matriz Institucional aplicada aos Ativos Intangíveis}

Conforme o arcabouço teórico emanado da teoria institucional, as instituições, mais facilmente compreendidas pelas regras impostas a um determinado ambiente, determinam o comportamento e a ordenação tanto das relações entre os indivíduos como entre as organizações. Considerando-se o objeto em estudo, no campo da contabilidade pode-se afirmar que a implementação da nova matriz institucional relativa aos ativos intangíveis advinda da IAS 38, influenciou nas relações dos agentes envolvidos neste ambiente. Esta nova norma formal foi reconhecida como regra especialmente pela sua força legalista, trazendo como resultado o condicionamento do comportamento individual e coletivo dos atores envolvidos no ambiente contábil aos padrões desta regra.

Mesmo considerando-se que a presença de padrões normativos vigentes implicitamente condiciona os procedimentos a serem adotados pelas empresas, o processo de institucionalização da nova matriz institucional relativa aos intangíveis foi observado diferentemente em cada empresa da amostra. Contudo, mesmo se observando uma grande variação nos índices de conformidade aos padrões contábeis na amostra, os resultados indicam que em geral as empresas buscaram se adaptar as novas configurações do ambiente institucional. Os exercícios após 2008 revelam a escolha pela nova norma. Os anos de 2010 a 2012 além de apresentarem os maiores índices, demonstram certa estabilidade nesta conformidade. 
Estas evidências vêm a comprovar os escritos de Peng (2003) que afirma existir duas fases no processo de institucionalização de uma regra. Na primeira fase há certa resistência no uso da nova proposição, utilizando-se frequentemente a regra anterior paralelamente a nova regra. A segunda fase é caracterizada pelo reposicionamento da empresa e a tendência de convergência total a nova regra. Já as afirmações de Schmidt (2008), Thelen (2009) e Bell (2011) sobre o processo da mudança institucional podem ser relacionadas às evidências identificadas neste estudo. Estes autores afirmam que este processo é caracterizado pelo continuísmo, reprodução e manutenção das instituições podendo ocorrer momentos ou situações de descontinuidade.

Em se tratando do aspecto social e econômico, a normatização formal dada para o reconhecimento dos ativos intangíveis, além de indicar o que as empresas devem acatar, estabelece um padrão de legitimidade para as empresas. Sendo assim, nos casos identificados em que não há a perfeita incorporação desta matriz institucional, as empresas podem estar assumindo o risco de enfrentar possíveis conflitos que podem resultar na perda da sua qualidade econômica. Conforme exprimem Crubellate (2007) e Polo e Vásquez (2008), a conformidade com o que está dado em uma instituição é fator decisivo na redução de incertezas nas relações econômicas e condiciona a sobrevivência das empresas no ambiente no qual estão inseridas.

É possível afirmar que a adoção da nova matriz institucional que parametriza as práticas contábeis relacionadas aos intangíveis (IAS 38 e CPC 04) proporcionou uma maior distinção desses ativos. Paralelo à isso, as evidências deste estudo demonstram que o aumento nos níveis de conformidade das empresas da amostra aos parâmetros obrigatórios para o reconhecimento dos ativos intangíveis, está diretamente ligado a capacidade desta instituição em minimizar a problemática da harmonização contábil para este procedimento. Observa-se, porém, que mesmo que a sua presença seja considerada compulsória, há a manutenção de regras anteriores em alguns casos, o que demonstra a resistência das empresas em aderir à uma nova configuração institucional.

\section{Considerações Finais}

Esta pesquisa teve por objetivo analisar a conformidade de uma amostra de empresas brasileiras de capital aberto pertencentes ao IBOVESPA à matriz institucional exigida para o reconhecimento de ativos intangíveis. O período examinado compreende os anos de 2006 a 2012, o qual se caracteriza por envolver as principais alterações nas normas contábeis relativas à intangíveis.

Buscando trazer maior solidez ao trabalho, analisou-se o reconhecimento dos ativos intangíveis a partir dos pressupostos da teoria institucional, condicionantes do contexto organizacional (MACAGNAN, 2013), especialmente pela utilização de regras. A perspectiva institucional pode ser empregada como base de estudos empíricos em diferentes contextos, como aqueles que envolvem as estratégias de legitimação empregadas pelas organizações e os processos de institucionalização (CARVALHO; VIEIRA; SILVA; 2012). Sendo assim, este estudo buscou relacionar as regras adotadas pelas empresas, neste caso as normativas sobre intangíveis, e a repercussão dessa utilização para o reconhecimento dos referidos ativos.

Considerando as evidências identificadas, se comprova que a implementação da nova matriz institucional sobre os intangíveis, advinda especialmente da IAS 38, repercutiu nas 
práticas adotadas pelas empresas brasileiras. Para o período analisado, observa-se que as maiores diferenças nas práticas adotadas ocorreram após o ano de 2010, com a vigência do CPC 04.

Embora a amostra seja composta por empresas de capital aberto que estariam orientadas a adotar as normas internacionais de contabilidade (IAS 38 para os intangíveis) conforme deliberação CVM n $\mathrm{n}^{\mathrm{o}}$ 488/2005, entre os anos 2006 e 2009 utilizavam-se diferenciados procedimentos contábeis: aqueles que se reportavam exclusivamente à legislação brasileira e aqueles que se aproximavam das normas internacionais. A partir de 2010, se constata uma maior unicidade dos procedimentos adotados pelas empresas, possibilitando inferir que se buscou, na maioria dos casos, a adequação aos requisitos do CPC 04/2010.

Conforme itens evidenciados nas notas explicativas e nos balanços patrimoniais das empresas, identifica-se um aumento gradual no nível de conformidade aos padrões estabelecidos pelo CPC 04 para o reconhecimento dos bens intangíveis. Isso se comprova pela análise dos padrões observados pela amostra, que em média tiveram um atendimento de $64 \%$ no período compreendido entre 2006 e 2012. Embora esse índice de conformidade seja considerado moderado, se observa uma tendência de elevação no atendimento aos padrões normativos, passando de 32\% no ano de 2006 para 84\% em 2012.

Em referência aos resultados da conformidade aos padrões exigidos para o reconhecimento dos ativos intangíveis, ressalta-se que dentro da amostra analisada já se adotavam padrões internacionais para este procedimento nos anos iniciais estudados. Entre 2006 e 2007 os níveis de conformidade estavam próximos a 30\%, sendo que em 2008 e 2009 apresentaram-se entre $60 \%$ e $69 \%$, o que comprova uma evolução na convergência à nova matriz normativa aplicada aos intangíveis.

Contudo, observa-se que embora o CPC 04/2010 tenha instrumentalizado metodologicamente os procedimentos contábeis para o reconhecimento dos ativos intangíveis, ainda há empresas que não seguem esses padrões. Estes reflexos identificados com a mudança na matriz normativa que trata desses elementos, especialmente em relação ao nível de conformidade aos padrões de reconhecimento dos ativos intangíveis, remete à uma análise institucional, sob a perspectiva da regra.

A normativa dada como regra, neste caso formal, foi absorvida pela predominância da amostra de forma gradual. Observa-se, porém, dentro do espaço longitudinal estudado, fases com menor e maior adesão à este regramento. Fatores informais poderiam estar relacionados aos casos de não utilização da nova normativa, consequência da ação individual e da própria cultura e costumes organizacionais.

Nos casos em que não há o enquadramento aos padrões formais, entende-se que as entidades estariam prejudicadas por tal opção, tanto em questões econômicas como em questões sociais. Na perspectiva econômica, os procedimentos adotados poderiam não contribuir positivamente na situação financeira e patrimonial da entidade. Quanto à perspectiva social, a entidade não estaria cumprindo com padrões de legitimidade perante o ambiente institucional no qual está inserida.

Concluindo, ressalta-se a utilização dos pressupostos da teoria institucional, especialmente aqueles advindos da perspectiva da regra, para explicar a convergência e a evolução na aderência às modificações da matriz normativa inerente ao reconhecimento dos ativos intangíveis. Como proposta de estudos futuros envolvendo esta temática, sugere-se 
análises com a expansão da amostra e a estruturação de método que possibilite inferir sobre o impacto econômico-financeiro pelo não reconhecimento de determinado ativo intangível, fruto da não institucionalização de padrões contábeis obrigatórios.

\section{Referências}

BELL, Stephen. Do we really need a new 'constructivist institutionalism' to explain institutional change? British Journal of Political Science, v. 41, n. 4, p. 883-906, 2011.

BOULERNE, Sandrine; SAHUT, Jean Michel. Les normes IFRS ont-elles amélioré le contenu informationnel des immatériels? Le cas des entreprises françaises cotées.

Comptabilité Contrôle Audit, v. 1, n. 16, p. 7-32, 2010.

BRASIL. Lei $\mathbf{n}^{\mathbf{0}}$ 6.404, de 15 de dezembro de 1976. Dispõe sobre as Sociedades por Ações. Brasília, DF, 15 de dezembro de 1976. Disponível em:

<http://www.planalto.gov.br/ccivil_03/leis/16404consol.htm>. Acesso em: 27 mar. 2013.

CARVALHO, Cristina Amélia; VIEIRA, Marcelo Milano Falcão; SILVA, Sueli Maria Goulart. A trajetória conservadora da teoria institucional. Revista Eletrônica de Gestão Organizacional, v. 10, n. especial, p. 469-496, 2012.

COMISSÃO DE VALORES MOBILIÁRIOS. Deliberação no 488 de 03 de outubro de 2005. Aprova o pronunciamento do IBRACON NPC n ${ }^{\circ} 27$ sobre demonstrações contábeis: apresentação e divulgações. Rio de Janeiro, RJ, 03 de outubro de 2005. Disponível em: $<$ http://www.cvm.gov.br/port/snc/deli488.pdf $>$. Acesso em: 02 out. 2011.

COMISSÃO DE VALORES MOBILIÁRIOS. Deliberação nº 644 de 02 de dezembro de 2010. Aprova o pronunciamento técnico CPC 04(R1) sobre ativo intangível. Rio de Janeiro, RJ, 02 de dezembro de 2010. Disponível em: < http://www.cvm.gov.br/>. Acesso em: 27 jun. 2012.

COMITÊ DE PRONUNCIAMENTOS CONTÁBEIS. Pronunciamento Técnico CPC 04 (R1): ativo intangível. Brasília, DF, 05 de novembro de 2010. Disponível em: < http://www.cpc.org.br/pdf/CPC04_R1.pdf>. Acesso em: 21 nov. 2011.

COMMONS, John R. Institutional economics. Madison: University of Wisconsin Press, 1934.

CRUBELLATTE, João Marcelo. Três contribuições conceituais neofuncionalistas à teoria institucional em organizações. RAC-Revista de Administração Contemporânea, ed. especial, p. 197-220, 2007.

GODOI, Christiane Kleinübing; BALSINI, Cristina Pereira V. A pesquisa qualitativa nos estudos organizacionais brasileiros: uma análise bibliométrica. In: GODOI, Christiane Kleinübing; MELLO, Rodrigo B.; SILVA, Anielson Barbosa (Org.). Pesquisa qualitativa 
em estudos organizacionais: paradigmas, estratégias e métodos. São Paulo: Saraiva, 2010. cap. 3, p. 89-112.

HALL, Peter; TAYLOR, Rosemary C. As três versões do neo-institucionalismo. Lua Nova: Revista de Cultura e Política, n. 58, p. 193-223, 2003.

GUERREIRO, Reinaldo. A abordagem institucional na contabilidade gerencial. Revista Contabilidade \& Finanças - USP, n. 40, p. 3-6, 2006.

INTERNATIONAL ACCOUNTING STANDARDS. IAS 38: intangible assets. Disponível em: $<$ http://eifrs.iasb.org/eifrs/bnstandards/es/2011/ias38.pdf > . Acesso em: 23 abr. 2013.

KMETEUK FILHO, Osmir. Pesquisa e análise estatística. Rio de Janeiro: Fundo de Cultura, 2005.

LENORMAND, Gaëlle; TOUCHAIS, Lionel. La pertinence des actifs incorporels avec les IFRS. Finance Contrôle Stratégie, v. 11, n. 2, p. 173-201, 2008.

LEV, Baruch; CAÑIBANO, Leandro; MARR, Bernard. An accounting perspective on intellectual capital. In: MARR, Bernard (Org.). Perspectives on intellectual capital. Burlington: Elsevier, 2005. cap. 3, p. 42-55.

MACAGNAN, Clea Beatriz. Teoría institucional: escrito teórico sobre los protagonistas de la escuela institucionalista de economía. Base, v. 10, n. 2, 2013.

MAHONEY, James; THELEN, Kathlenn. A theory of gradual institutional change. In: Explaining institutional change: ambiguity, agency and power. Cambridge: Cambridge University Press, 2010.

MEYER, John W.; ROWAN, Brian. Institutionalized organizations: formal structure as myths and ceremony. American Journal of Sociology, v. 83, n. 2, p. 340-363, 1977.

MOURTISEN, Jan; BUKH, Per Nikolaj; MARR, Bernard. A reporting perspective on intellectual capital. In: MARR, Bernard (Org.). Perspectives on intellectual capital. Burlington: Elsevier, 2005. cap. 5, p. 69-81.

NAKAMURA, Leonard. Intangibles: what put the new in the new economy? Federal Reserve Bank of Philadelphia Business Review, p. 3-16, 1999.

NORTH, Douglass. Custos de transação, instituições e desempenho econômico. Rio de Janeiro: Instituto Liberal, 1994.

NORTH, Douglass. Instituciones, cambio institucional y desempeño edonómico. México: Foundo de Cultura Económica, 1995. 
OLIVEIRA, Valdiney Alves; LEMES, Sirlei. Nível de convergência dos princípios contábeis brasileiros e norte-americanos às normas do IASB: uma contribuição para a adoção das IFRS por empresas brasileiras. Revista Contabilidade \& Finanças - USP, v. 22, n. 56. p. 155-173, 2011.

OLLIER, Corinne Bessieux et al. L'adoption em France dês normes IRFS relatives aux incorporales. Revue Française de Gestiont, n. 207, p. 93-110, 2010.

PENG, Mike W. Institutional transitions and strategic choices. Academic of Management Review, v. 28, n. 2, p. 275-296, 2003.

PETKOV, Rossen R. Initial identification of internally generated intangible assets in the context of the definitions of an asset and an intangible asset. Journal Theoretical Accounting Research, p. 1-10, 2011.

PETKOV, Rossen R. Competitive advantage from internally generated intangible assets measured at fair value Bulgarian small and médium size enterprises. Journal of Theoretical Accounting Research, v. 7, n. 2, p. 55-67, 2012.

POLO, Francisca Castilla; VÁZQUEZ, Dolores Gallardo. La decisión de divulgar intangibles a través de una estrategia de triangulación teórica. Estudios de Economía Aplicada, v. 26, n. 2, p. 79-104, 2008.

SOTO, Eutimio Mejía; SALAZAR, Carlos Alberto; GALVIS, Omar de Jesús. Comparación del tratamento contable de activos intangibles según diferentes organismos reguladores.

Estudios Gerenciales, n. 99, p. 89-104, 2006.

VEBLEN, Thorstein. A teoria da classe ociosa. São Paulo: Pioneira Editora, 1965.

VIEIRA, Diego Mota. Mudança institucional gradual e transformativa: a influência de coalizões de advocacia e grupos de interesses em políticas públicas. In: ENANPAD, 36, 2012, Rio de Janeiro. Anais... Rio de Janeiro, 2012.

WILLIAMSON, Oliver E. The new institutional economics: taking stock, looking ahead. Journal os Economics Literature, v. 38, n. 3, p. 595-613, 2000.

ZUCCOLOTTO, Robson; SILVA, Gustavo Melo; EMMERNDOERFER, Magnus Luiz. Limitações e possibilidades de compreensão da utilização das práticas de contabilidade gerencial por perspectivas da teoria institucional. Base, v. 7, n. 3, p. 233-246, 2010. 
